side of the problem that confronts him. This will mean a few minutes must be spent in explaining what is wrong, and what steps are to be taken to help the patient. The doctor should be as reassuring as the case will allow. The French aphorism sums it all up. 'Guerir quelquefois, soulager souvent, consoler toujours.' Finally, the patient should be asked if he has any other questions. The overall results of treating the whole patient, the emotional as well as the physical side of the problem, give the greatest satisfaction to all concerned.

\section{RERERENCE}

'Dewar, H. A. (1986) Personal Communication.

\title{
The Wisdom of Deterrence-a Reply to Jim Dyer
}

\author{
IAN J. Deary, Lecturer in Psychology, University of Edinburgh, 7 George Square, Edinburgh
}

Dr Dyer's attack on the policy of deterrence 'The Psychopathology of Nuclear War' Bulletin, January $1986^{1}$ leaves me confused. The claim of the Medical Campaign against Nuclear Weapons (MCANW), of which Dr Dyer is a prominent member, was that it would study and disseminate information on the medical effects of nuclear war and the effects of possessing nuclear weapons, but Dr Dyer's treatment of deterrence was neither of these: it was a series of criticisms of a defence policy. The policy of deterrence has kept the peace in Europe for $\mathbf{4 0}$ years and has been supported by every British government since the end of the 1940s. It is still supported by the majority of the British electorate. Still, this does not prevent Dr Dyer from dubbing it, 'nuclear madness' which calls for the 'restoration of sanity.' Elsewhere deterrence is called a 'degenerative state' and I have to assume that the author agrees with the following quote as he cites it without criticism: 'nuclear weapons constitute the greatest immediate threat to the health and welfare of mankind.'

Even if we allow Dr Dyer the luxury of 40 years of immediacy then the three most immediate threats to the health and welfare of mankind during that time have been famine/overpopulation, Stalinism and conventional warfare (150 wars, none in Europe, have been fought since World War II with the loss of over $10,000,000$ lives). In support of the claim that nuclear weapons are the greatest immediate threat to the health and welfare of mankind from now on we might have expected a detailed consideration of the following three possibilities:

1. The money spent on nuclear weapons is money that would be spent on bettering the lot of man if we got rid of those weapons.

2. Deterrence is a system that is more dangerous than a given system $X$. This possibility would require a detailed discussion of how we would get to system $X$ from our deterrence system and why we have not done so.
3. Deterrence is an irrational system, not merely an unpredictable one.

Although they are not included in Dr Dyer's account there are those (e.g. Sidel ${ }^{2}$ ) who have argued that the nuclear build-up has contributed to global famine and to the lack of medical aid being directed to the Third World. These commentators, though, do not appear to have considered the following points.

1. The problem with nuclear weapons is not that they are ruinously expensive. As Steven Walt ${ }^{3}$ has said, 'compared with other armaments, nuclear weapons are small, light, cheap and extremely destructive.' Dyer's claim that, 'One Pershing missile costs $\$ 5$ million, the cost of immunising one million Third World children against preventable infectious diseases,' misses the point.

2. Most, and all British, promises of nuclear reduction are backed up by a second promise of an increase in conventional strength. In Britain that would mean two things. First, at a conservative estimate, the defence budget would triple. (The Labour Party in Britain have already stated that if they win the next election and attempt to carry out their defence policies they have no prospect of cutting defence expenditure-Sunday Times, 30 March 1986.) Second, the only realistic way to boost defences to pre-disarmament levels would be to bring back conscription. I have never heard those who ask for nuclear weapons to be replaced by increased conventional strength mention this: I wonder why?

3. Calls for nuclear disarmament on the grounds of cost are odd when one knows that nuclear weapons only take $10 \%$ of the British defence budget. It is conventional weapons that threaten the foreign aid budget, not nuclear weapons. 
The next possibility we have to examine, since Dr Dyer has failed to, is the likelihood that deterrence is a more dangerous system than some other conceivable system $X$.

Dr Dyer's claim that the medical role in the nuclear debate is in 'preventive medicine' needs further elaboration. 'Nuclear weapons,' he says, 'are surely no less important than alcohol, cigarettes and car seat belts' and, further, '... doctors are not neutral and dispassionate in relation to life and death, disease and health.' It is here that Dr Dyer oversteps the MCANW remit. I agree with his opinion that we need a fuller appreciation of the medical effects of nuclear explosions and the psychological effects of the possession of nuclear weapons. As to the former, the more we discover the less anyone now conceives of a winnable nuclear war. This supports deterrence, not the reverse. On the latter point, the fact that we might suffer some psychological trauma from the mere threat of these weapons is not desirable, but it does not follow from the existence of this nuclear neurosis-if it exists-that we would be in a better state without them.

In his spurious use of the 'preventive medicine' argument Dr Dyer covertly makes the following statement to his readers; deterrence is more likely to lead to war and largescale suffering than something else. The something else, the system $X$, is never specified and we are left to assume that there exists some achievable utopia which will come about when the madness and, therefore, the irrationality of deterrence have been exorcised; one would have to be mad to live under nuclear threat in preference to utopia. Any of us who supports deterrence might give up our lasting peace if $\mathrm{Dr}$ Dyer were to offer us a convincing cure for our nuclear madness. We assume, after all, that Dr Dyer has a potion to offer.

Since Dr Dyer talks of a system we expect an analysis of that system. It is the defenders of deterrence who have shown subtlety here. A system continues to 'work' by checks and balances, by fine tuning and modesty. Intellectual radicalism (man's belief in the omniscience of his own rationality) kills delicate social systems. The biological systems thinker and geneticist C. H. Waddington ${ }^{4}$ realised this and was able to separate his desire for utopia from his sense of what was the least dangerous system in a real, and therefore imperfect, world:

'I can see no escape from the conclusion that the major ethical task for today is to ensure that a major war does not occur.

... it by no means follows, from the remarks about the destructiveness of warfare made above, that the most sensible policy for any of the major powers would be an immediate abolition of all its armed forces.'

To claim that one has seen a system's irrationality implies that the perceiver's world model has calculated and adjusted hundreds, perhaps thousands of important variables (recall that the average number of bits of information held in human short-term memory is seven); that he has come up with an untangling and resetting of the system; and can predict the outcomes of the new system for at least, say, 40 years.

Instead of the necessary analysis we were offered quotes by J. H. Thomas, Seneca and a one-off comment by the WHO (not an argument) but no analysis. Dr Dyer appears as someone who sees deterrence as a malaise of our civilisation. Unlike the unilateralist he lacks the courage to wield the scalpel and unlike the multilateralist he offers nothing to suggest that he has appreciated how far the malaise might now be a part of our system and that we might even depend upon it for our survival. Perhaps his fear of horizontal proliferation, which I share, is the beginning of such an awareness.

No proofs are given for the assertion that we have arrived at a, "world whose folly has brought about the threat to this future and which seems unable to remove the threat, or even not to care about it.' It is more likely that nuclear weapons are the crystallisation of system wisdom, albeit a deeply regrettable wisdom. If Dr Dyer is simply singing a lament here I will accompany him. But these are just noises; the appearance of caring, and the unfair accusation that others do not care, while they do their best in the circumstances. Posturing on the moral high ground is not enough, if there is a better way we must hear about it. The quote above reminds me of a recent meeting where Dr Dyer and I found that we agreed on most medical and psychological aspects of the nuclear threat until the following question was asked: 'Why are people so opposed to peace?' Of course, only madmen are opposed to peace. But peace is only a devalued word when asked in a question like that. To believe in 'peace' does not equate with being against deterrence, and monopolising the word will not wash. Let me say here what should be obvious: I am for peace, I detest weapons of any kind, particularly nuclear weapons, but in advance of a massive change in our ability to verify arms reductions I still submit to the Churchillian dictum that 'peace has become the sturdy child of terror.' Being 'for peace' in current sloganeering terms is more likely to result in being 'for war.'

It is convenient for Dr Dyer, instead of critically examining deterrence, to provide a catalogue of pseudopsychiatric terms to dismiss the advocates of deterrence. We suffer from denial, paranoid defence, reluctance to step out of line and a lack of comprehension. Nowhere is there consideration given to the fact that most of the caring and intelligent people in the UK, USA and USSR have thought about these issues and come to the sad conclusion that, for now, deterrence is the safest way to proceed. The advocate of deterrence is also considered psychologically disturbed for being 'apparently detached and objective.' Does this purported manifestation of denial lead to the testable hypothesis that the truly rational nuclear theorist has the appearance of a gabbling lunatic?

The further discussions of the safety of deterrence versus some other system is best discussed in conjunction with the third issue: is deterrence irrational or unpredictable? This can be cleared up by looking at the logic of deterrence and the development of NATO's policies from the 1950s to date.

The first nuclear policy that led to deterrence was that 
of massive retaliation. If an enemy launches any nuclear warhead then the immediate and only response is a massive retaliatory strike that would inflict unacceptable damage on the initial aggressor. This was refined to the concept of mutually assured destruction whereby both sides accepted that each had the potential and the willingness to destroy each other's civilisation if there was a sufficient stimulus to do so. Eventually the mutually assured destruction strategy became unconvincing. It was clear to NATO that the threat to launch a massive retaliatory attack after, say, the launch of one warhead by the Warsaw Pact was unconvincing. It was just not believable that the West would commit certain suicide after what might be an error or an attack that went no further. Thus NATO evolved the policy of flexible response.

Flexible response says to a potential aggressor that there are three levels of response that I can respond with if I am attacked but I am not going to let you know what my policy is. In other words, a potential aggressor does not know if he will be met by conventional weapons, theatre nuclear weapons or strategic nuclear weapons. This is a more believable strategy and it mirrors the discovery that in nature animals, in games theory analyses, never give away their intentions in their aggressive displays. It is the maintenance of believability that led NATO to state that it could never commit itself to a no 'first-use' of nuclear weapons. If it were to commit itself to such an undertaking then it would say to the USSR that whatever the conventional losses suffered by NATO it would never escalate. This would be the signal for the Warsaw Pact to capitalise on its conventional superiority in the event of a confrontation over, say, scarce resources or a political disagreement.

Thus deterrence rests on a combination of credibility and uncertainty. The potential enemy must accept that one has the willingness to use nuclear weapons in response to an attack. But this is not equivalent to an intention to use these weapons, as the philosopher Anthony Kenny ${ }^{5}$ discusses. It is enough for the enemy to believe that there is even a chance that unacceptable losses might be inflicted upon him. Deterrence, then, rests on the possession of huge weapons systems that are not intended for use, but which an enemy accepts could be used given a severe enough attack. How severe, he has no idea; and in his anxiety to prevent a nuclear response he takes extra care to get nowhere near the possible levels of aggression that might result in such a response. Paradoxically, deterrence rests on the love of an administration for the safety of its own people.

None of this is mad or irrational: nor is it a degenerate system. It is analogous to other weapons systems that have evolved in nature. Both the red stag and the bighorn sheep have huge antlers and horns, respectively, that are lethal if used on a member of the same species. The bighorn sheep spends about $10 \%$ of its total metabolism in growing its horns. And yet these weapons are hardly ever used. Both species carry out their 'fights' by ritualised roars and displays. For a cheater or an interloper there is always the threat that they might be used; he does not take the chance.

Of course, the animals have certain safeguards that we do not. First, the antlers and horns are metabolically expensive and only fit animals can make and make use of them. We no longer have this assurance with nuclear weapons. Horizontal proliferation might lead to an unstable regime with a nuclear weapon. This is among the most frightening of all the possible nuclear scenarios. Second, the occasional failure of this biological deterrence, while disastrous for the animal involved, will not wipe out the species. We do not have this flexibility and we cannot assume that we can survive even one error in our system. But again this supports deterrence, not the opposite. It behoves us to realise that the system of protection we have evolved is a subtle web of interdependent forces. If we tamper with it we risk lighting the fuse of a time bomb. I do not claim that deterrence is perfect but I do emphasise that it is a bomb that is not ticking. I would want to be very sure that anyone who did not like the system had understood it very well before fiddling with it.

As I understand it, MCANW was set up to make us aware of the health effects of nuclear war and weapons. That they are terrifying is not contentious. That the health professionals would be useless after even the smallest of nuclear explosions is not contentious. That the psychological sequelae of nuclear warfare would be terrible I am not inclined to doubt. If there is a safer world to be had then we all want it and frankness about the human condition will provide a basis for its realisation. As a tentative step to a cautious and creative multilateralism I would commend the work that Steven Salter ${ }^{6.7}$ has put into the development of the disarmament ideas of Singer $^{8}$ and Calogero'. Realistically, Salter enumerates the enduring psychological barriers that prevent disarming starting:

1. mutual suspicion;

2. the fact that the 'enemy' always appears to be stronger;

3. the anxiety that surrounds verification;

4. no two sides can agree on the relative defence value of their own or their opponent's weapons systems.

Allied to these are the proposed size of most weapons reductions; so much so, in fact, that the bigger the proposal (Reagan's 'zero-option' or Gorbachev's 'no weapons by the year 2000') the more we are sure that one side is proposing it in the knowledge that the offer won't be taken up.

Also, the loopholes in previous agreements have led to little real arms reduction; reduction in delivery system numbers leads to multiple warheads, and so on. Rather than to couch these in Freudian jargon Salter makes them into the strengths of his disarmament system. If humans think in these ways, reckons Salter, then it is better to capitalise on what is known than to hope for a universal change in thought processes.

Salter's system is based on the model that children use when attempting to share a piece of cake. Children, despite their absolute happiness being not much affected by whether there is cake for tea, are very sensitive to relative benefits. If one gets a bigger piece than the other then distress results. Children apply a simple rule: I cut, you choose. 
The cutter then takes care to cut the pieces as equally as is possible. The other tries to detect any difference to gain advantage.

The cake-sharing theory of slow multilateral nuclear disarmament works along similar lines. Each side makes an inventory of its nuclear arms and calls the total $100 \%$. A proportion of this sum is assigned to each warhead and the value of each warhead is called the military value percentage: say, $0.04 \%$ for a cruise missile. Each side then sends their list to the other and invites them to choose $1 \%$ of the total for the first round of disarmament. At the end of the first year, say, each side will have $99 \%$ left. The following things might well result:

1. There will be no increase in the perceived threat from the other side as $99 \%$ of weapons are just as deterring as $100 \%$.

2. Despite the very small change there would be a huge psychological shift as the world would now be one that was disarming, but still deterring.

3. Unlike the result of all other disarmament schemes the perceptions of change would lead to increased confidence instead of increased insecurity.

The last of these results because the side that drew up the list assigned military value percentages to weapons in the exact proportion to their ability to offer security. The other side will pick the $1 \%$ that they perceive to be the most dangerous and they will thus feel that they have got more than $1 \%$ in their slice. Thus at the end of the first round each side feels more safe and deterrence still operates. In this scheme things move very slowly. Either side can call a halt at any time if it felt it was being cheated. But cheating would have disadvantages. In the first stages cheating would have very little benefit - the odd one or two percentage pointsbut the loss in terms of international loss of face would be great. Also the cheater who did not disarm risks new methods of verification finding him out.
The other method of cheating would be to assign false values to the initial military value percentage list. This could be used to over-value a system that one side particularly wanted to keep. The cost is, of course, that something else must be undervalued and the cheater risks offering this bargain to the other side.

The slowness with which Salter's method would proceed is its greatest strength. As long as the risks of horizontal proliferation, imperfect verification, prefabricated missiles (which, disassembled might be deemed not to count as part of the list), plutonium stockpiles and the knowledge to make nuclear weapons exist then a 'nuclear-free' world will be a more dangerous place than it is at present. But these problems would be many rounds away in the Salter scheme and there is no reason why a start could not be made soon. The wisdom of deterrence would continue to operate within the lifetimes of most of us. If the above problems were not solved by the time the numbers of warheads were getting to a critically low level then deterrence could be left to operate at this new low level, preserving the safety of the planet as it has done for the last four decades.

\section{REFERENCES}

'DVER, J. (1986) The psychopathology of nuclear war. Bulletin of the Royal College of Psychiatrists, 10, 2-5.

${ }^{2}$ SideL, V. (1985) Destruction before detonation: the impact of the arms race on health and health care. Lancet, it, 1287-1289.

${ }^{3}$ WALT, S. (1986) Why clever schemes don't work. Issues, II, 83-92.

'WADDnNGTON, C. H. (1960) The Ethical Animal. London: Allen \& Unwin.

${ }^{5}$ KENNY, A. (1985) The Logic of Deterrence. London: Firethorn.

-Salter, S. (1984) Some ideas to help stop World War III. (Unpublished).

' (1986) Stopping the arms race: a modest proposal. Issues, II, 74-82.

'SInGER, E. (1963) A bargaining model for disarmament negotiations. Journal of Conflict Resolution, 7, 21-25.

${ }^{9}$ Calogero, F. (1977) A novel approach to arms control negotiations? Proceedings of the 27th Pugwash Conference, 1-10.

\section{Diploma in Child and Adolescent Psychiatry}

A one year course leading to a Diploma in Child and Adolescent Psychiatry will start in January 1987. This annual course will be run jointly in London by the Institute of Psychiatry and the Institute of Child Health. It will cover diagnosis and treatment of children and adolescents with psychiatric disorders including those with physical illness and chronic handicap; assessment of community needs in relation to child mental health with a view to planning or implementing psychiatric services in the participant's own country; teaching and training medical and paramedical workers. The course will be particularly suitable for paediatricians and psychiatrists intending to set up or work in child mental health services in developing countries. Good English essential. Bursaries may be available. Applications should be returned by 1 September 1986. Further details: Dr A. D. Cox, Department of Child Psychiatry, Institute of Psychiatry, De Crespigny Park, Denmark Hill, London SE5 8AF. 